\title{
El mito de Europa en los textos literarios clásicos
}

\section{The myth of Europe in Greek and Roman classical literature}

\section{Alejandro Bancalari Molina}

Universidad de Concepción. Concepción, Chile

abancala@udec.cl

\section{RESUMEN}

El artículo tiene como propósito indagar sobre el relato del mito de Europa en diversos textos literarios de la antigüedad grecorromana, cuál fue la acepción más conocida y utilizada y el significado mismo que se desprende del término. Asimismo, se examina cómo va oscilando la idea de Europa desde una leyenda a una realidad geográfica e histórica concreta en el mundo romano.

Palabras clave: Europa, relato, mito, teónimo, corónimo, espacio geográfico.

\section{ABSTRACT}

The aim of this article is to study the story of the myth of Europe in various texts of ancient Rome and Greece, its most widespread and common conception, and the meanings which can be deduced from this term. This article also examines how the idea of Europe shifts from being a legend to being a concrete geographical reality in the Roman world.

Keywords: Europe, story, myth, theonym, toponym, geographical space.

Recibido: 23.12.2010. Aceptado: 03.09.2011.

* Este artículo se inserta en el proyecto Fondecyt No 1080104, titulado: "Europa romana: antecedentes y esencia de una identidad y primera unidad europea en el mundo romano (siglos III a.C. - III d.C.)". 


\section{SOBRE LA LEYENDA}

- uropa, el nombre en torno a la leyenda que da origen al continente, es Cuno de los personajes femeninos ampliamente testimoniados por los escritores antiguos. Se conocen al menos diez protagonistas y diez versiones del término, intentando algunos de ellos racionalizar sus relatos y descripciones.

¿En qué consiste el relato literario más célebre y cuál ha sido la historia más probable del mito de Europa a pesar de las complicaciones y ambigüedades difíciles de descifrar, precisar e interpretar? En las costas de Fenicia (actual Líbano), un grupo de jóvenes mujeres caminaban, jugaban y recolectaban flores ("azucenas"). De todas ellas, sobresalía una de "rubia cabellera", de belleza resplandeciente y de estirpe real. Era la hija de Telefasa y de Agénor, rey de Tiro. Sin embargo, otras versiones sostienen que no era hija de este último, sino de Fénix ${ }^{1}$. Desde lo alto, Zeus observó a estas jovencitas y quedó prendado de Europa por su hermosura (característica común en toda la tradición literaria y mitológica antigua). Usando una de sus triquiñuelas, descendió a la playa y metamorfoseado se transformó en un dócil toro blanco con cuernos similares a un creciente lunar. Moscos (poeta siracusano del siglo II a.C.), narró la aventura de Europa, exclamando en los inicios de su obra: "De la inocente princesa se coloca delante; cariñoso juguetea y los hombros le lame. Ella lo tocó y en hacerle caricias se recrea; con las manos enjuga de su boca la espuma que odorífera blanquea, y fascinada imprime en su embeleso en la frente del toro cándido beso. Él muge de placer; y su mugido de la flauta imita el penetrante armónico sonido dobla las manos y la cauda agita, le muestra con el cuello retorcido la vasta espalda, y a subir la invita..." (2001. Europeia: XXII-XXIII). De esta manera, la heroína y sus compañeras comenzaron a acariciar al toro, particularmente Europa que al verlo apacible y sumiso se subió a su lomo.

Ovidio describe en forma ejemplar la seducción y subraya el aspecto erótico de Zeus: "No casan bien la majestad y el amor, no pueden convivir en la misma sede; por tanto, abandonando la solemnidad del cetro, Júpiter, padre y soberano de los dioses, que empuña en su diestra los rayos de tres puntas, que sacude el mundo con un movimiento de su cabeza, adopta la forma de un toro, y mezclándose entre los novillos, muge y pasea su belleza sobre la hierba tierna. Su color es exactamente como el de la nieve cuando

${ }^{1}$ Diversos autores antiguos consideran que Europa en realidad era nieta de Agénor, pues uno de los hijos de éste, llamado Fénix, habría sido el padre de la bella y joven princesa. Cfr. Homero, Iliada, XIV, 321-322; Moscos, Europeia, VI-XV; Apolodoro, Biblioteca mitológica, III, 1, 1. 
no lleva las huellas de duros pies ni ha sido derretida por el lluvioso Austro; el cuello se yergue poderoso, entre las patas cuelga la papada, y los cuernos son pequeños, sí, pero tales que se diría que están hechos a mano, y más diáfanos que una gema transparente. No hay amenaza en su rostro ni fiereza en su mirada: su semblante es pacífico. La hija de Agénor se asombra de su belleza y de que no presente batalla, pero, a pesar de su mansedumbre, al principio no se atreve a tocarle; luego se le acerca y tiende unas flores hacia su blanco hocico. Se regocija el enamorado, y mientras llega el esperado placer colma de besos sus manos; apenas, apenas puede ya diferir el resto, y tan pronto juguetea brincando sobre la verde hierba, como reposa su níveo costado sobre la arena dorada. Poco a poco, a medida que Europa abandona su miedo, unas veces le presenta su pecho para que lo acaricie con su virginal mano, y otras le ofrece sus cuernos para que los enlace con guirnaldas recién trenzadas. También se atrevió la regia princesa, sin saber a quién oprimía con su cuerpo, a sentarse sobre el lomo del toro: el dios, sin que se note, se va alejando de la tierra y de la parte seca de la playa, luego moja sus falsos pies en las olas de la orilla, se aleja un poco más, y por fin se lleva a su presa por las aguas del mar abierto. Ella está llena de miedo, y mientras se la lleva se vuelve a mirar hacia la costa que va quedando atrás, con su mano derecha se agarra a un cuerno, y la izquierda reposa sobre el lomo. Sus ropas tiemblan agitadas por la brisa" (1987. Metamorfosis: II).

Una vez que la hija de Agénor estaba en el lomo del toro, éste, aprovechando su oportunidad y en forma veloz, surcó las aguas del Mediterráneo. A pesar de los gritos de Europa, aferrada a sus cuernos, llegaron a la isla de Creta. Es el viaje de Europa "raptada" del Oriente al Occidente y que tendrá una simbología especial ${ }^{2}$. Será en la localidad de Gortina (al sur de Cnossos, Creta) cuando el toro o Zeus, retomando su forma humana, se une a Europa junto a una fuente (gruta Dictea), bajo un plátano sagrado, con hojas siempre verdes. Como producto de la unión de los dos, nacieron tres hijos: Minos (nombre genérico del rey cretense y de la civilización minoica como la primera de Europa), Radamantis y Sarpedón.

Se le atribuye, asimismo, la maternidad de Carno y la de Dodón. Posteriormente, Asterión (rey de Creta), se casó con Europa (convertida entonces en la primera reina de Creta), adoptando a sus hijos. Todos estos hechos significativos hicieron que Zeus donara a Europa tres presentes. Talo (que significa "sol"), el gigante de bronce, protector de las costas cretenses;

\footnotetext{
2 Para una mayor profundización del argumento, véase Somville (1994), Sordi (1998), Grammatico (2003), Bauman (2006).
} 
Laelaps, un perro adiestrado que no soltaba su presa y una jabalina que nunca erraba en el blanco, simbolizando tal vez las diversas guerras.

Mientras tanto, en Fenicia, Agénor, indignado por el rapto de su hija, prepara una expedición con los hermanos de ésta (Cadmo, Fénix, Cílix y Taso) con el firme propósito de ir en su búsqueda y hacerla regresar. De los cuatro hermanos, la saga de Cadmo es la mayormente descrita por los autores antiguos, pero la más compleja. Cadmo se dirige al oráculo de Delfos, recomendándole seguir una vaca con un signo blanco de luna llena en sus costados. Se detuvo en Beocia y fundó Tebas, atribuyéndole la transmisión del alfabeto de Fenicia a la hélade. Entre sus aventuras se destaca el encuentro con el dragón que exterminó a sus compañeros, pudiendo él vencerlo. Tomó como esposa a Harmonia, dando origen a la dinastía tebana. Tanto Cadmo como los otros hermanos, no tuvieron buenos resultados en la búsqueda de Europa. Así, a Taso se le vincula con la isla del mismo nombre en el mar Egeo; a Fénix corresponde el epónimo de Fenicia y Cílix que da origen a la zona sur de Asia Menor, Cilicia.

\section{EL PROBLEMA ETIMOLÓGICO Y SEMÁNTICO}

Otro de los aspectos que presenta una diversidad de interpretaciones y polémicas, dice relación con el significado y sentido del término Europa. De acuerdo a la tradición más difundida, hoy por cierto no aceptada, el nombre Eủ hebraico "ereb", de diversos significados, tales como: poniente, puesta de sol, atardecer, oscuridad y sobre todo, "occidente" (Luciani, 1986: 23). Muchos lo asociaron a Érebo, el dios de las tinieblas infernales. Si aceptamos esta explicación semántica, el concepto fue introducido y difundido por los fenicios desde las costas del corredor sirio-palestino por todo el Mediterráneo hasta el estrecho de Gibraltar. Todos los territorios incorporados y descubiertos en ese "espacio" comprendían genéricamente la hipotética sinonimia Europa = Occidente.

Muy clarificadoras son las palabras de Luis Diez del Corral, en su clásico ensayo El rapto de Europa, al señalar: "El término Occidente es impreciso, relativista, traslaticio; está llamado a emigrar como el astro solar de que procede la imagen. América es más occidental que Europa como, de otra parte, el Lejano Oriente es más oriental que el Cercano, cuna de la civilización; pero, aunque fuera posible la perduración de la cultura creada por Europa en otras tierras, aunque se perfeccione y aun culmine en ciertos aspectos en 
el Nuevo Mundo, lo que a nosotros, europeos, nos interesa vitalmente son las formas de vida radicadas en nuestras viejas tierras. Ni Europa como expresión geográfica, ni Occidente como mera expresión cultural, sino Europa occidental" (1974; 121-122).

Si bien, como señalamos, el problema del origen semítico del nombre Europa, para muchos filólogos, lingüistas e historiadores, constituye un caso cerrado, los menos consideran que todavía es un argumento "abierto". Por cierto, son todavía demasiados los matices para sostener conclusiones fundadas. De partida, desde el punto de vista estrictamente estructural: "Europa es un nombre griego; no es improbable de que se trate de una transcripción griega de un nombre semítico. Sin embargo, no demostrable fonéticamente" (Milani, 1986: 10).

Otra hipótesis sobre la etimología de la palabra Europa: el vocablo griego "eurus" significa "amplio", "ancho" y se conecta al epíteto homérico de Zeus europa, que quiere decir Zeus de amplias y profundas miradas ("ops" = "mirada”, el que ve a lo lejos). De ahí que la forma femenina de Europa, indica a una mujer con un hermoso semblante, amplio y de grandes ojos (Mikkeli, 2002: 13). Criticada también esta interpretación, no existe un consenso mayoritario para establecer, con precisión y fundamentación, una acepción del término Europa.

\section{ENTRE EL TEÓNIMO Y EL CORÓNIMO}

Como hemos afirmado, el vocablo Europa deriva de la princesa y heroína de Fenicia, bastamente testimoniado por los escritores clásicos, versión que proviene de los mitos y leyendas, dando origen al teónimo de Europa. No obstante esto, Europa es un término polisémico, pues además de circunscribir y caracterizar lo mitológico-divino, presenta también la acepción geográfica (=corónimo o topónimo). Será así como el término Europa, geográficamente hablando, se empleó por primera vez en un himno homérico a Apolo en Delfos, escrito en el siglo VI a.C, señalándose: "Aquí (Crisa, al pie del Parnaso) me propongo construir un hermosísimo templo, que sea oráculo para los hombres, los cuales me traerán siempre perfectas hecatombes -así los que poseen el rico Peloponeso, como los que habitan en Europa y en las islas bañadas por el mar-cuando vengan a consultarlo; y yo les profetizaré lo que verdaderamente está decidido, dando oráculos en el opulento templo" (Himno Homérico a Apolo: III, 250-251 = 290-291).

En este contexto, Europa viene a significar "tierra amplia"; la Grecia con- 
tinental en contraposición a las islas del Egeo y al Peloponeso (que los mismos helenos consideraban una isla). Con ello se circunscribe el "continente" (Cassola, 1998: 41) a un espacio territorial que corresponde a la Grecia central y que por extensión incluiría a la zona norte de la hélade, Macedonia y Tracia. Así, la noción geográfica original del concepto Europa demarcaría a la región central de $\mathrm{Grecia}^{3}$ y en una acepción más amplia a la península balcánica. Este sentido y significado original, ya hacia fines del mismo siglo VI a.C., tomará otro rumbo en relación con la aceptación, proyección y cambio del término. Será Hecateo de Mileto hacia el 510 a.C., quien afirmaba que en el gran disco solar de la Tierra, circundada por el océano, se distinguían tres sectores: Asia al oeste; Libia (=África) al sur y Europa al norte. La diferenciación geográfica de Hecateo es esencial en la distinción de las tres áreas o continentes de la ecúmene, pero sobre todo fija una tradición por escrito donde Europa es más que la Grecia central y meridional. Le correspondió el mérito al logógrafo Hecateo de Mileto ser el primero en definir y caracterizar (aunque sea puntualmente) el concepto de Europa como una entidad geográfico-continental que se extiende desde el río Tanais (actual Don) hasta el estrecho de Gibraltar ${ }^{4}$. Lamentablemente para nosotros, gran parte de la obra de Hecateo está perdida y sólo se conservan algunos fragmentos y pasajes citados por Heródoto de Halicarnaso. Por ello, el padre de la historia tendrá un lugar clave en la descripción y análisis del continente europeo.

Su naturaleza incansable de conocimiento, de viajero y de investigador, permiten a Heródoto descubrir la ecúmene y particularmente Europa. Ésta, a diferencia de África, no ha sido circunnavegada y ninguno puede conocer con precisión los límites septentrionales y occidentales de acuerdo a la tradición jónica. En particular, Hecateo en su obra Periegesis señala que el confín oeste de Europa está constituido por la localidad de Tarteso (al sur de la península Ibérica) y regiones limítrofes a las columnas de Hércules 5 . La frontera nororiental con la región de Escitia y el río Tanais, representan la frontera entre Asia y Europa. La realidad del desconocimiento e igno-

${ }^{3}$ El mismo sentido de antítesis de Grecia central como sinónimo de tierra ancha y continental en oposición a las islas y la península del Peloponeso, aparece nítidamente en la descripción de la conformación étnica y número de contingentes en las fuerzas navales panhelénicas de las guerras médicas. Cfr. Heródoto, Historia, VIII, 42, 1.

${ }^{4}$ Píndaro en una oda a Zeus advertía a los navegantes que no fueran más allá de las columnas de Hércules y de Cadiz, a un mundo desconocido y oscuro, aconsejando girar hacia las zonas seguras de Europa. Así, para el poeta, Europa era equivalente a toda la costa septentrional del Mediterráneo. Véase, Mikkeli (2002: 15).

${ }^{5}$ Heródoto, Historia III, 115, 2; IV, 45, 1 y 4, considera que no existe un mar al occidente de Europa. Respecto del límite entre Europa y Africa, está claro: las columnas de Hércules. 
rancia de sectores lejanos y periféricos del continente europeo (sobre todo el centro-norte), tanto en el ámbito geográfico como étnico y cultural, fue producto del escaso radio de acción del proceso colonizador de las poleis griegas. Ellas ocuparon esencialmente la zona costera del Mediterráneo y el sur de Europa, no penetraron hacia el interior y por consiguiente no se aventuraron a abrir o conocer otras rutas comerciales al corazón mismo de Europa. Fueron los romanos quienes exploraron, describieron y finalmente habitaron el entroterra del continente ${ }^{6}$, debido a una política gradual de urbanización y romanización.

Heródoto visualiza el continente europeo como extendido y amplio; el mayor de los tres ${ }^{7}$, en una clara óptica y visión de una trilogía helénicamediterránea-europea, en la cual los griegos ejercen una influencia y matriz radical, en el sentido de constituirse etnográfica y culturalmente como la mejor zona de vida civilizada. De esta forma, los escritos de Heródoto nos confirman que el concepto de Europa significaba una unidad geográfica, pero también étnico-cultural bastante más completa y valorizada que los escritores precedentes. A pesar de que en su tiempo permanecen muchas dudas e imprecisiones, nos advierte: "Por lo que a Europa respecta, nadie en el mundo sabe si está rodeada de agua por todas partes, ni existen datos que especifiquen de dónde ha tomado ese nombre ni quién fue el que se lo impuso, a no ser de que admitamos que esa zona tomó su nombre de la tiria Europa (refiriéndose a la protagonista del mito del rapto que relataremos a continuación); pero en ese caso, con anterioridad carecía de nombre, como las otras partes del mundo. No obstante, esa mujer era, sin lugar a dudas, originaria de Asia y no llegó hasta esta tierra que actualmente los griegos denominan Europa, sino que desde Fenicia llegó tan sólo a Creta y de Creta a Licia. En fin, sobre este tema basta con lo dicho, pues para las partes del mundo utilizaremos los nombres que la costumbre ha generalizado" (Historia: IV, 45, 4-5).

Europa es un término polisémico: por una parte significa "heroína"; por otra, "espacio geográfico". Los estudiosos, hoy en día, no se ponen de acuerdo si fue la heroína quien otorgó el nombre al territorio, es decir una mujer en el amplio aspecto con una característica continental o, a la inversa, si

\footnotetext{
${ }^{6}$ Polibio, Historias, II, 15-16 y III, 36-5, describe en cierta medida la Europa occidental de la ecúmene.

${ }^{7}$ Hecateo considera que la ecúmene estaba dividida en dos continentes: Asia y Europa, que corresponde a la separación de su obra en dos libros. Si bien Heródoto critica y polemiza con la tradición jonia de la división del mundo en tres continentes, finalmente la acepta. "Cuando dicen que la tierra tiene en total tres partes: Europa, Asia y Libia” (II, 16). Véase, Cassola (2001: 9-15).
} 
fue la región la que dio el nombre a la heroína. Filippo Cassola cree que la historia más probable es la segunda (1998: 46). En otras palabras, el nombre de Europa deriva del corónimo y ha precedido al teónimo Europa. Su culto ha sido venerado, originariamente, en el espacio territorial llamado Europa, representando y personificando el símbolo de la región misma (centro y norte de la Hélade). De esta manera, Europa surge como un mito (el rapto) y también como realidad geográfica. Sin embargo, será a partir de las guerras médicas (494-448 a.C.) que el concepto, idea y noción de Europa presentan un profundo topos político, étnico y cultural. Es la determinación y contraposición entre helenos (=europeos) y persas (=asiáticos), definida y caracterizada sobre todo por Heródoto y Esquilo ${ }^{8}$. Por cierto, en la identificación del conflicto Asia-Europa están presentes múltiples parámetros diferenciadores y valorados indistintamente por los historiadores?

Así, el continente europeo compatibiliza, esencialmente, los sectores del Mediterráneo, identificados con la libertad política y ciudadana con usos y costumbres urbanas y con el manejo de la palabra que coincide con la idea misma de oikúmene. Asia, por consiguiente, se identifica con la esclavitud y con un imperio gigantesco y despótico, donde no existe la libertad y el manejo adecuado de la palabra para discutir. Es la dicotomía: helenos v/s bárbaros, Occidente v/s Oriente, en la cual, las guerras médicas y particularmente la batalla de Maratón ${ }^{10}$, se convierte en el símbolo de la libertad y del triunfo de Europa sobre Asia; a partir de lo que Gehrke denomina "historia intencional" ${ }^{\prime 1}$.

${ }^{8}$ El dualismo Europa-Asia será uno de los tópicos de los escritores antiguos, los que, a su vez, confrontan el binomio Occidente v/s Oriente. Cfr. Luppino-Manes (2000: 45-60).

${ }^{9}$ Entre otros véase Hartog (1994), Pagden (2002), Hubeñak (2004).

${ }^{10}$ El triunfo de Maratón (490 a.C.) se proyecta a Europa: en ella, los atenienses habían combatido por la eleutheria y por los logros de la civilización y la cultura helénica, pero también por Europa y Occidente. Es la propia percepción europea que se mantiene por dos mil quinientos años. Metafóricamente, Maratón es un canto a la libertad y una auténtica caracterización del triunfo de Europa sobre Asia, de Occidente sobre Oriente. De ahí que la batalla se transformó en un símbolo de identidad, la cual representa las cualidades especiales y los logros, pero también incluye un contraste con los "otros". El mito que se entiende como "historia real".

${ }^{11}$ Los estudiosos de la "historia intencional" consideran que ciertos relatos o tradiciones, que una comunidad determinada o una sociedad consideran como constituyentes de su propio pasado y son vitales para la identidad de un grupo, constituyen lo que denominan "historia intencional". $\mathrm{Al}$ examinar las guerras médicas, nos damos cuenta de que se va formando una cadena exitosa desde Maratón a Platea, que oscila entre el mito y la historia, de cómo los griegos, particularmente los atenienses, vencieron al poderoso imperio persa. Se construye una imagen y una simbología con la batalla de Salamina y Maratón, del triunfo de la libertad sobre la esclavitud y el despotismo persa, legitimando la supremacía de la Hélade. Esta "historia intencional" se encuentra en el "corazón de su identidad" y Maratón se convirtió en el "símbolo de las guerras persas" y con el tiempo representa la superioridad de Occidente y Europa sobre el continente asiático. Véase, Gehrke (2009: 85-99). 


\section{DEL RELATO MÍTICO A LA REALIDAD HISTÓRICA}

Es imposible precisar históricamente en qué momento se desarrolló y se difundió latamente la visión del rapto de la princesa fenicia y cómo llega finalmente a la Hélade. Como sabemos, los diversos mitos son transmitidos en forma oral. El narrador o poeta dejaba libre su imaginación y creación para completar ciertas lagunas, añadiendo otros relatos y contextos. Igualmente, podía cercenar y ejercitar narraciones en la transmisión oral de estos acontecimientos, lo que presupone muchas décadas y siglos de mutaciones y cambios por doquier. Si bien la datación a la cual alude el mito de Europa, como señalamos, es incierto, las recientes investigaciones lingüísticas, históricas y arqueológicas, nos permiten situarla aproximadamente a mediados del segundo milenio antes de Cristo. A partir del 1500 a.C., en la zona del Mediterráneo oriental, se conformó una red e interconexión de pueblos y culturas sin precedentes. Un fenómeno único e inusual en la historia antigua: un equilibrio de poderes y de "estados pares" que conformaron una red interconectada de influencias, articulaciones económicas complejas e intercambios culturales, haciendo de la zona mencionada un espacio "internacional" y de un tráfico continuo de redes y de movilidad (Van de Mieroop, 2005: 117-140). Será con la cultura Creto-Micénica que el mito de Europa, asociado al hecho religioso y sagrado del culto al toro, comience un periplo de intento de "racionalizarlo" (Passerini, 2002: 13). Al encontrar ciertas verdades históricas encubiertas por mitos, se percibe cómo se van agregando nuevos elementos, aspectos y leyendas que se refieren a diversas épocas, pero que tienen su punto de inflexión hacia mediados del segundo milenio. Como se explicó, será con Hecateo y Heródoto que surgirán narraciones continuas del mito y los lectores tendrán un grado de conocimiento de los eventos descritos y analizados en los relatos.

En el mundo romano, si bien persiste entre los escritores la idea difundida del teónimo y corónimo de Europa, comienza a germinar una noción con un sentido mucho mayor, de una incipiente identidad vinculada a los territorios (europeos) del orbe romano. De partida, el erudito Varrón (1990), del siglo I a. C., investigando sobre Asia, la define con la siguiente fórmula: "Asia quae non Europa": "Asia es aquella que no es Europa" (Lengua latina: V, 16). En esta contraposición, lógicamente, es valedero asimismo lo opuesto (Europa es aquella que no es Asia). Fórmula que insiste en marcar la diferenciación entre dos continentes desde la perspectiva geográfica y etnocultural.

Con las empresas de Julio César, al conquistar y recorrer las tres Galias 
y Britania, más los éxitos imperiales y políticos de Octavio Augusto al consolidar los territorios del Rin y el Danubio, surge un mayor conocimiento y amplitud de Europa. El modelo augústeo y su consecuente pax Romana, estabilidad e integración romano-provincial, crearon los fundamentos necesarios para proyectar y concretar con vitalidad, en el siglo de los emperadores Antoninos, el gradual y civilizador proceso de romanización. Es necesario precisar que no debemos confundir este proceso con una simple conquista o incorporación, sino entenderlo como la integración, asimilación y homologación, por parte de los diversos pueblos nativos, a una nueva entidad, sintiéndola como propia. Se va constituyendo una cosmovisión romana común, más o menos transversal en el imperio, implicando un estilo de vida y una cierta conciencia de vivir dentro del orbis Romanus, formando parte activa y dinámica de éste.

Ahora bien, proféticas y significativas son las palabras de un paso de Horacio (1997), donde describe a Europa llorando por su situación de raptada y, sobre todo, por la dignidad de su nuevo estatus, que es precisamente otorgar el nombre a un continente, señalando: "deja de sollozar y aprende a soportar la buena suerte, que una parte del globo recibirá tu nombre" (Odas a los Galatas: III, 27).

Europa, como espacio geográfico, es el núcleo central y más antiguo del orbis Romanus. El dominio de Roma aparece como legítimo y se colocan en evidencia los efectos considerados positivos sobre la vida moral y material de las poblaciones nativas. La Urbs asume y se convence de su papel histórico de integrar a todos los pueblos en su cultura, que en el momento aparece como única y superior. Era la concepción de mundo que tenían, con algunos matices, entre otros autores clásicos, César, Estrabón, Plinio el Viejo, Tácito, Elio Arístides y Menandro. En el imperio comienza a surgir un sentimiento colectivo de pertenencia y de participación en una misma cultura y un mismo cuerpo político-jurídico. Por lo mismo, el proceso gradual de romanización va asociándose cada vez más a la noción e idea de una Europa mediterránea, sobre todo en el Occidente ${ }^{12}$.

En general, los escritores antiguos destacaron las bellezas y los elementos superiores del continente europeo; más aún si este espacio formaba parte de la ecúmene romana. El naturalista, Plinio el Viejo, en el siglo I d.C., explica la idea y noción de Europa, por qué se considera la "madre o nodriza" de diversos pueblos y cómo es la "más hermosa de las tierras", ocupando la

${ }^{12}$ Desde la clásica obra de Mazzarino (1947), pasando entre otros por Chabod (1961), Sordi (1998), hasta Bispham (2008), Europa es sinónimo de Occidente. 
mitad o un tercio del mundo, seguido de África y Asia. Dentro de sus particularidades, Plinio (1995) describe desde una óptica geográfica los cuatro golfos que componen el continente. Especial relevancia le otorga a Italia, sosteniendo que es "una tierra que es criatura y a la vez madre de todo el mundo, elegida por voluntad de los dioses para hacer el cielo mismo más luminoso, congregar imperios antes esparcidos, educar los hábitos sociales y con la comunidad de lengua, llevar a entendimiento a gentes de hablas tan diferentes y salvajes y aportar la civilización al género humano: en una palabra, a que fuera una sola en todo el orbe la patria del conjunto de las naciones" (Historia Natural: III, 5, 39). Por otra, podemos vislumbrar en Plinio, desde una perspectiva moral, cultural y etnográfica, cómo Europa ${ }^{13}$ comienza a vincularse y a asociarse con el mediterráneo y a ser considerado un territorio medular y generador del orbis Romanus.

\section{CONSIDERACIONES FINALES}

El mito de la princesa Europa, con más de tres mil años de antigüedad, ha estado presente y ampliamente descrito en las fuentes literarias. Más allá de esta acepción, la otra, como espacio territorial, ha dado origen a un continente que, sin duda, ha sido el centro y fulcro del pensamiento y de la cultura occidental. "Europa, siempre joven y bella, conjuga en sus diversos rostros los diversos aspectos de su destino y las contrastantes, temibles, tectónicas fuerzas que dirimen, a lo largo del tiempo, el maravilloso despliegue de su naturaleza y de su historia" (Grammatico, 2003: 18). En el fondo, Europa es una forma de vida, una forma de pensar y actuar con una fuerza magnética centrífuga y centrípeta. No debe dar la espalda a su génesis, formaciones, basamentos y tradiciones del mundo clásico. Debe continuar, consciente o inconscientemente, imitando algunos estereotipos o imágenes que le ayuden a encontrarse a sí misma y a su propia identidad. En fin, debe incansablemente, como lo hizo en sus orígenes la heroína Europa, continuar con esa travesía redescubriéndose y reinventándose. Es su misión y, al mismo tiempo, como señala Zygmund Bauman (2006), una "aventura inacabada".

Estimamos que es oportuno conocer aún más al viejo continente como realidad histórica, forma mentis, con sus raíces, evolución y tradiciones, toda vez que nuestro país firmó en el año 2002 un acuerdo con la Unión Europea.

\footnotetext{
${ }^{13}$ Son múltiples los estudiosos que consideran al imperio romano como formador y el que prefigura con antecedentes y elementos directos a Europa. Entre otros, véase Delmas (1984), Le Goff (1995), Cantarella (1996), Rietbergen (1998), Sordi (1998), Dahlheim (2008).
} 
Éste es un gran salto en el desarrollo económico, con un mercado de 500 millones de habitantes (consumidores) y de 27 estados miembros, lo que representa un mayor acercamiento en las políticas económicas y gubernativas, como asimismo en lo científico y cultural. Así, Europa no debe ni puede perder su rumbo misionero, como una forma de vida, por la capacidad de vivir con los otros y de no tener fronteras fijas. Su esencia radica en que no existe una Europa sino "variadas Europas" (Delmas, 1984: 34). Con desaciertos terribles y funestos, acusada de eurocentrismo y con logros perennes y universales, Europa continúa su periplo y "aventura”, relacionándose con su capacidad humana, primigenia, creadora y globalizadora.

George Steiner (la figura excelsa del humanista europeo), nacido en Francia, de una familia judía de lengua alemana, educado en los Estados Unidos y profesor en Ginebra y en Cambridge, publicó su visión de la Europa actual ${ }^{14}$. En ella intenta resumir con un mínimo de ideas, tradiciones y costumbres, lo que es y representa Europa en cinco grandes aspectos. 1) Europa es, ante todo, un "café repleto de gentes y palabras", donde se habla, se discute, se reflexiona y se practica la "civilizada tertulia"; de ahí nacieron todos los sistemas filosóficos y revoluciones. 2) "El paisaje caminable, la geografía hecha a la medida de los pies". Europa ha tenido una medida humana donde se puede caminar y recorrer. "La naturaleza no aplastó al ser humano" y el paisaje no tendió a separarlos, sino más bien los acercó. 3) "Colocar a las calles y plazas el nombre de grandes estadistas, científicos, artistas y escritores del pasado". Algo inconcebible en los Estados Unidos. Esto explica la "abrumadora presencia que el pasado tiene en la vida europea". El peso de la historia, "lo viejo y lo gastado por los siglos tiene un valor". 4) "Descender simultáneamente de Atenas y de Jerusalén”, de la razón y de la fe; de la tradición que humanizó la vida. El peso de una doble tradición: "la ciudad de Sócrates y la de Isaías". 5) Su visión "pesimista, fatalista”. Una convicción escatológica que luego de crecer, madurar y alcanzar el apogeo, sobrevendrá la ruina y el final de Europa. A Steiner lo atormenta la "pesadilla de la historia europea", la uniformación cultural como consecuencia de la globalización (al desaparecer la variedad lingüística, como el mejor patrimonio del viejo continente); el despotismo del mercado y otros elementos negativos.

El Premio Nobel de Literatura 2010, Mario Vargas Llosa, gran entusiasta de la integración europea, plantea que el viejo continente es el "único gran

\footnotetext{
${ }^{14}$ Un texto sugerente, iluminador y polémico, donde retrata y explica lo que es actualmente Europa. Véase Steiner, 2008 [2004].
} 
proyecto internacionalizador y democrático" (2008: 15). Sus artes y creaciones deben seguir compartiéndose, entrecruzándose y amalgamándose entre los diversos pueblos de la actual sociedad global. El viaje de la princesa Europa entonces debe continuar hacia lo infinito e inacabado como una aventura secular y perenne. Se constituye finalmente en una forma mentis irradiadora e integradora de la vida misma.

\section{REFERENCIAS}

Apolodoro. 1997. Biblioteca Mitológica, III. Madrid: Alianza

Bauman, Zygmund. 2006. Europa. Una aventura inacabada. Madrid: Lozada.

Bispham, Edwuard (ed). 2008. Europa romana. Barcelona: Crítica.

Brague, Rèmi. 1995. Europa, la vía romana. Madrid: Gredos.

Cantarella, Eva. 1996. El peso de Roma en la cultura europea. Madrid: Akal.

Cassola, Filippo. 1998. Il nome e il concetto di Europa, en Convegno per Santo Mazzarino. Roma: L'erma di Bretschneider, pp. 9-54. 2001. "Il concetto di Europa nelle fonti classiche". En Urso,

Gianpaolo (ed.). Integrazione Mescolanza rifuto. Incontri di popoli, lingue e culture in Europa dell'Antichità all'Umanesimo. Roma: L'erma di Bretschneider, pp. 9-15.

Chabod, Federico. 1961. Storia dell'idea d'Europa. Bari: Laterza.

Dahlheim, Werner. 2008. En la cuna de Europa. Libertad urbana en la antigua Roma. Madrid: Siglo XXI.

Delmas, Claude. 1984. La civilización europea. México D.F.: Fondo de Cultura Económica.

Diez del Corral, Luis. 1974. El rapto de Europa. Una interpretación histórica de nuestro tiempo. Madrid: Alianza.

Gehrke, Hans Joachin. 2009. "From Athenian indentity to European ethnicity -The cultural biography of the myth of Marathon". En Derks, Ton y Roymans, Nico (eds.). Ethnic Constructs in Antiquity: The role of power an tradition. Amsterdam archaeological studies 13, Amsterdam: Amsterdam University Press, pp. 85-99.

Grammatico, Giuseppina. 2003. "Lo clásico como sustento integrador de la nueva Europa”, en Europa 1, pp. 9-22.

Hartog, Françoise. 1994. "Conoscenza di sél conoscenza dell' altro”. En Guilaine, Jean y Settis, Salvatore (eds.). Storia d' Europa. Torino: Einaudi, vol. 2, pp. 891-923. 
Heródoto. 1995. Historias, III-IV y VIII. Madrid: Gredos.

Himno Homérico. 1998. A Apolo, III. Milano: Rizzoli.

Homero. 1995. Ilíada, XIV. Madrid: Gredos.

Horacio. 1997. Odas a los Gálatas, III. Bologna: Zanichelli.

Hubeñak, Florencio. 2004. "Europa: una mirada a lo lejos", en Europa 2, pp. 257-278.

Le Goff, Jacques. 1995. La vieja Europa y el mundo moderno. Madrid: Alianza. Luciani, Ferdinando. 1986. "La presunta origine semitica del nome Europa". En Sordi, Marta (ed). L' Europa nel mondo antico. Milano: Università Cattolica del Sacro Cuore, pp. 12-26.

Luppino-Manes, Emma. 2000. "Il dualismo Europa-Asia nella tradizione dei tragici di V sec. a.C.; da Eschilo ad Euripide". En Sordi, Marta (ed.). Studi sull'Europa antica. Alessandria: Dell'Orso, pp. 45-60.

Mazzarino, Santo. 1947. Fra Occidente e Oriente. Firenze: La nuova Italia.

Mikkeli, Heikki. 2002. Europa. Storia di unidea e di unidentità. Bologna: Il Mulino.

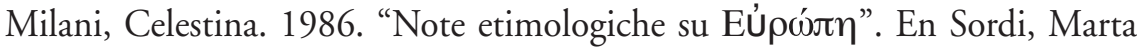
(ed). L' Europa nel mondo antico. Milano: Università Cattolica del Sacro Cuore, pp. 3-11.

Moscos. 2001. Europeia, XXII-XXIII. Milano: Rizzoli.

Ovidio. 1987. Metamorfosis, II. Madrid: Akal.

Pagden, Anthony (ed.). 2002. The idea of Europe. From Antiquity to the European Union. Cambridge: Cambridge University Press.

Passerini, Luisa. 2002. Il mito d'Europa. Radici antiche per nuovi simboli. Firenze: Giunti.

Plinio el Viejo. 1995. Historia Natural, III. Madrid: Gredos.

Polibio. 1981. Historias, II-III. Madrid: Gredos.

Rietbergen, Peter. 1998. Europe. A cultural history. London: Routledge.

Somville, Pierre. 1994. "Le mythe d'Europe". En Perrin, Michelle (ed). Lidée de l'Europe au fil de deux millénaires. Paris: Beauchesne, pp. 13-19.

Sordi, Marta. 1998. "Europa e occidente nel mondo classico". En Poignault, Rémy y Wattel- De Croizant, Odile (eds.). D'Europe à l'Europe I. Le Mythe d'Europe dans l'art et la culture de l'antiquité au XVIII siècle. Paris: Tours, pp. 55-58.

Steiner, George (ed.). 2008 [2004]. La idea de Europa. Madrid: Siruela, $3^{\text {ra }}$ ed.

Van de Mieroop, Marc. 2005. "The Eastern Mediterranean in Early Antiquity”. En William Harris (ed.). Rethinking the Mediterranean. Oxford: Oxford University press, pp. 117-140. 
Vargas Llosa, Mario. 2008. "Una idea de Europa”. En Steiner, George (ed.). La idea de Europa. Madrid: Siruela, $3^{\text {ra }}$ ed., pp. 9-17. Varrón. 1990. Lengua Latina, V. Barcelona: Antrophos. 